\title{
An Integrated Intervention for the Treatment of Serious Psychosomatic Illnesses Such As Cancer
}

\author{
Fabiola Fortuna \\ Individual and group Psychoanalist \\ Member of the S.E.P.T. (Société d'étude de psychodrame psicothérapeutique) \\ Member of the Association of European Psychanalystes (Association des Psychanalystes Européens \\ S.I.Ps.A. Teaching Membership (Italian Society of Analytical Psychodrama) (Società Italiana Psicodramma Analitico) \\ I.A.G.P. Membership \\ Member of the Selection Committee for admission to the CIPA School of Psychotherapy in Rome
}

*Author of Correspondence: Fabiola Fortuna; claudia.parlanti@alice.it

Received 12 February 2019;

Accepted 13 March 2019;

Published 15 March 2019

\begin{abstract}
Background: The term "psychosomatic"often is improperly used: currently psychosomatic means both the set of morbid states that can create mental illness, and the psychic implications in the aetiopathogenesis of organic diseases.

Personally, I think it is more useful to focus on the question from this last point of view. I think also that the real psychosomatic disorders should also include cancer, cardiovascular diseases and multiple sclerosis.

This does not imply that the etiopathogenesis of these diseases might solely be of a psychic nature, but we should also hypothesize this possibility, along with hypothesizing the contributing factor of psychological causes.

Actually the hypothesis most credible is that the serious organic diseases such as cancer, originate from three main factors: genetic, environmental and psychic.

Methods: The N.M.P.M.P. (New Psychotherapeutic Method Psychosomatic Diseases) is a integrate method that consists in individual collogues, psychophysical relaxation techniques and group psicotherapy with analytical psychodrama created by Eugenie and Paul Lemoine.

Results: Even though it is not possible to get statisical data, the NMPMP's results are very promising: the method are generated a significant improvement in health conditions for patients; from alleviation of chemotherapy symptoms to complete remission of the symptoms related to neoplasie.

Conclusions: The clinical experience described shows to be strategically indispensable an integrate psychological intervention for patients suffering from serious organic diseases.
\end{abstract}

Keywords: psychosomatic, psycotherapy, psycoanalisys, cancer, Modigliani, integrated method, analytical psychodrama

\section{Ambiguity in psychosomatic: historical confusions}

To face the issue of the body, keeping adequately in mind its specificity, it is essential to refer to the theoretical dimensions which underlie psychosomatics and deepen them. Psychosomatic is the term used to refer to an orientation of the medical, psychological and psychoanalytic sciences, aimed at emphasizing the aspect of the psychophysical totality of individuals.

The term "psychosomatic" was conceived in 1818 by J. C. Heinroth. Currently psychosomatic means both the set of morbid states that can create depressive situations in the subject, and the psychic implications in the etiogenesis of organic diseases.
Personally, I think it is more useful to focus on the question from this last point of view, also considering the distinction between functional disorders and psychosomatic disorders, being the first ones linked to an altered functioning of an organ and related to the mood, while in the latter ones there is a first organ impairment.

\section{An innovative challenge}

In my opinion, the real psychosomatic disorders should also include cancer, cardiovascular diseases and multiple sclerosis. This does not imply that the etiopathogenesis of these diseases might solely be of a psychic nature, but we should also hypothesize this possibility, along with hypothesizing the contributing factor of psychological causes. 


\section{Many authors have dealt with the close interaction between psychological factors and cancer}

For example, we can mention C.B. Bahnson and M.B. Bahnson (1966), who pointed out that in the structuring of the personality of individuals who then develop cancer, there is a massive use of defensive mechanisms, such as repression and denial; afterwards, Le Shan pointed out that people who developed cancer had previously suffered significant losses or, anyhow, particularly painful separations. An important contribution was given by the French psychoanalysts Marty and M'Uzan, who noted that individuals who developed psychosomatic disorders, presented a ghostly poverty of "reverie" and a rigid separation between conscious and unconscious dimensions, that is, they ultimately had a lack of representations.

These subjects are often people who apparently seem totally well adjusted, individuals for whom the term "normal" would be used to define them.

They mainly use an operative, concrete thought, in which the emotional aspects are almost absent or poorly developed.

Biondi and collaborators have also made their own contribution, and it seems interesting to mention one of their research, in which it emerged that people suffering from fibrocystic disease gave answers to the neurotic scales of M.M.P.I., which produced an elevation to the questionnaire on anxiety that was higher, if compared to those with breast cancer.

It is also essential to mention the longitudinal research conducted by Caroline Bedell Thomas, which began in 1946 on a sample consisting of a large number of students and of a control group.

After almost thirty years of research, the researcher proved how the profile of the subjects who developed cancer was actually superimposable to that of the suicides subjects.

In Italy one of the most important psychoanalysts who dealt with psychosomatics has been no doubt Claudio Modigliani (19162007), a true pioneer whose thought, however, resulted far too innovative in the clinical-cultural context of the time: this, combined with the scarcity of written texts, has made his theories guiltily neglected.

\section{Claudio Modigliani's thinking}

Claudio Modigliani was one of the founders of the reconstituted Italian Psychoanalytical Society (SPI). Disciple of the Jungian psychoanalyst Ernst Bernhard, Modigliani was a pioneer in the study of psychosomatics.

Modigliani's approach to serious organic diseases is still today an unprecedented and complex approach, in which elements typical of classical metapsychology are integrated with empirical observations that are typical of the medical-scientific approach. From this "contamination", associated with intuitions and reflections resulting from his great clinical experience, he has advanced several decades of research, aimed at verify the consistency between the fundamental concepts of psychoanalysis with the recent discoveries in neuropsychiatry and neuropathology.

One of Modigliani's most interesting contributions is his theory of psychosis and neurosis as a model of health.
Inspired by his clinical experience, as well as by some brief but significant annotations by Jung, in which the latter described how in patients with serious psychic pathologies a significant decrease of organic pathologies was found, overtime Modigliani developed a hypothesis according to which there could be a possible "negative correlation" between psychic illness and organic disease.

At the World Congress of the International College of Psychosomatic Medicine, held in 1975, Modigliani asserted that ultimately also psychosis is a life-saving process, performed by nature, "therefore, a biological defense, which, however heavy it may be, it nevertheless requires the maximum respect (...) and, on the other hand, if the psychic picture may appear to be in parallel much improved and clear of the most severe symptoms, this should not be misleading. In fact, they are temporary pseudo-issues that hide a critical phase consisting precisely in the impairment of psychic defenses and in the regression to somatic levels that are inaccessible. "[1] The psychosomatic question, therefore, is substantiated by the possibility of consciously enduring psychic suffering: neurosis and psychosis, with their load of defenses and regressions, would paradoxically represent a "model of health". This would depend on the fact that non-perceivable suffering could undermine the integrity of the subject, assuming a possible passage between the psychic and the soma.

In brief, according to Modigliani, serious organic diseases such as cancer, originate from three main factors: genetic, environmental and psychic.

With the evolution of genetic manipulation techniques, it has been proved that pathologies are linked to particular gene sequences: in this field many researches are involved.

Similarly, the correlation between deteriorated environmental conditions and the onset of serious diseases has been proved; intervening in this field requires a complex of political, economic and social actions.

Finally, the psychic factor remains: acting on it can crucially influence the clinical course of a psychosomatic patient.

Modigliani, in his long clinical and theoretical experience, has turned his attention to those recurrent intrapsychic aspects in his patients, in which he detects a profound "inability" to tolerate the psychic sufferings that cause a very strong "unconscious" suffering.

The particular activation of unconscious defense mechanisms such as negation and repression, leave the situations of conflict at the unconscious level: mechanisms of the ego defense become therefore mechanisms of offense of the unconscious and of the instinctual life.

Modigliani linked the observation of this condition of "inertia" of the subject to the conviction that there is a close correlation between the instinctual life of the subject, the Id, and the immune system, thus hypothesizing the existence of a transition from the unconscious situation of the patient to the bodily Ego.

According to Modigliani, patients who develop serious psychosomatic illnesses are those where the process called "masochistic homeostasis" (a process in good part unconscious that aims at a sort of balance in the acceptance of suffering) is lacking, so that a systematic rejection of conflicts leads to the point that death is preferred to suffering. 


\section{For Modigliani another crucial aspect to be investigated is that of stress}

It is known that the term stress, introduced by Hans Selye in 1936, indicates a "general adaptation syndrome", ie a nonspecific biological response of the organism following to the activation of the pituitary - adrenal - thymus gland axis, where the latter is an essential gland in the immune system.

Modigliani observed, and the most recent research confirms it as well, that stress can cause a collapse of the immune defenses: from the dynamic-economic point of view, stress is the rupture of a balance that until then was functional to the subject's life, while from the metapsychological point of view it can be considered originated from a reflux of aggressiveness that, up to a certain moment, had been used to reach a particular purpose (a professional goal, an economic or personal success). Once this purpose has been accomplished, the load of aggressiveness can create an emotional traffic jam that may be turned against the subject himself.

Modigliani suggested the usefulness of exploring the unconscious economy of aggression in order to suggest "alloplastic" transformations (ie modifications which are external to the subject) being generally reduced in those patients "autoplastic" capacities, ie the ability to convert into a somatic symptom their own psychic issues.

«... the psychosomatic patient always ignores the origin of his illness ....... at the base of these [pathological] forms there is always a psychic component that in many diseases is crucial, while in others it is only collateral»

\section{New experiences in view of Lacan's thinking}

Jacques Lacan has dealt with the somatic disease from a brand new and original point of view.

According to Lacan, those who develop somatic diseases live an "unbearable" life of which they are unaware, due to exaggerated narcissistic dimensions that can prevent the processes of separation: subjectivity is crushed by the desire of the Other, which becomes the dimension to be privileged, to detriment of oneself.

Then comes the non articulated jouissance to the signifier, which instead attaches itself to the question of need: the subject is no longer free.

Symptoms are formations of the unconscious that have a structure of language and therefore presuppose the possibility of substitution and metaphor (like to say "there is one thing instead of another"), instead, in the case of the "psychosomatic question", we must speak of "phenomena", in which it seems that in the body itself it is written that something which the subject can not read.

Psychosomatic phenomena are linked to language effects that are however out of subjectivation: the cure must therefore put the patient in the condition of "reading" what is actually "written" in the body.

People who develop cancer are usually psychologically destroyed even though they are not aware of it; it would seem to have to do with melancholy, in which there is the complete impossibility to process the mourning.
In order to "treat" the serious psychosomatic pathologies, it seems necessary to offer an intervention that considers with greater force the psychic, as well as the organic, aspects of the diseases, so that the energies and personal resources for the construction of a project may be activated in the patients, in such a way that the disease can become an opportunity for a rebirth.

\section{Suggestive techniques}

In 1841 Sir Brad called hypnosis (from the Greek hypnos) the techniques of fixation of the gaze and of suggestion. Charcot first and Freud later, they resumed all this and tried to treat hysterical disorders with hypnosis.

According to Modigliani, people who develop serious psychosomatic illnesses are characterized by "masochistic homeostasis", in which the hegemony of a persecutory archaic Super Ego prevails, hence it is difficult for them to undertake classical psychoanalytic treatment. "The suggestion - Professor Claudio Modigliani says - is often the language that the Super Ego can understand, the only one that psychosomatic patients are able to listen to, at least at the beginning".(2)

\section{Conclusions}

After many years of experience with psychosomatic patients, I have developed a method that combines Modigliani's hypotheses, the analytical psychodrama and the psychophysical relaxation techniques.

The N.M.P.M.P. (New Psychotherapeutic Method Psychosomatic Diseases) aims to empower the conscious and unconscious psychic resources of the individual, so that he can recover the desire to live more desirously with consequent reactivation of the functioning of the immune system.

It is good to remind that the intervention with severe psychosomatic subjects is delicate and therefore a long training is essential: these are patients who have a very high level of psychic pathology and therefore they need excellent listening skills.

\section{References}

[1] ("Psychosomatic illness as an alternative to psychosis " - "La malattia psicosomatica come alternative alla psicosi"-. Round table "Therapy in psychosomatic medicine" by F. Antonelli, Proceedings of the 3rd World Congress of the International College of Psychosomatic Medicine, Rome, Sept. 1975).

\section{Author Profile}

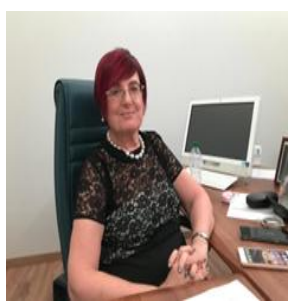

Fabiola Fortuna is an Individual and group Psychoanalyst. S.I.Ps.A. Teaching Membership (Italian Society of Analytical Psychodrama) (Società Italiana Psicodramma Analitico);-Member of the Selection Committee for admission to the CIPA School of Psychotherapy in Rome ;Magazine Director "New Notebooks of Psychoanalysis and Analytical Psychodrama" ("Nuovi Quaderni di 
Psicoanalisi e Psicodramma Analitico") (S.I.P.sA. Official Magazine). Professor at COIRAG Postgraduate School, Rome . Member of the International Association of Analytical Psychology
(IAAP in 2008). Member of the Sept (Psychotherapeutic psychodrama study company) (Société d'étude de psychodrame psicothérapeutique) 